\title{
Pengaruh Model Problem Based Learning Terhadap Hasil Belajar Siswa Pada Materi Pokok Suhu Dan Kalor Di Kelas X Semester II SMA Negeri 1 Percut Sei Tuan T.P 2014/2015
}

\author{
Ida Wahyuni ${ }^{1)}$ dan Siti Maysarah ${ }^{2)}$ \\ Jurusan Fisika FMIPA Universitas Negeri Medan \\ Maysarahsiti8@gmail.com
}

\begin{abstract}
ABSTRAK
Penelitian ini bertujuan untuk mengetahui pengaruh model Problem Based Learning terhadap hasil belajar siswa pada materi pokok suhu dan kalor. Jenis penelitian ini adalah quasi eksperimen dengan two group pre-testt-posttest design. Populasi dalam penelitian ini adalah seluruh siswa kelas X semester II yang terdiri dari 5 kelas. Pengambilan sampel dilakukan dengan cara cluster random sampling yaitu kelas X-MIA 1 sebagai kelas eksperimen dan kelas X-MIA 5 sebagai kelas kontrol. Instrumen yang digunakan yaitu tes hasil belajar yang berbentuk essay test dengan jumlah 10 soal. Nilai rata-rata hasil belajar siswa yang diberi perlakuan dengan model Problem Based Learning adalah 76,53 dan dengan pembelajaran konvensional adalah 69,7. Berdasarkan hasil analisis perhitungan uji t, menunjukkan bahwa ada pengaruh model Problem Based Learning terhadap hasil belajar siswa pada materi pokok suhu dan kalor.
\end{abstract}

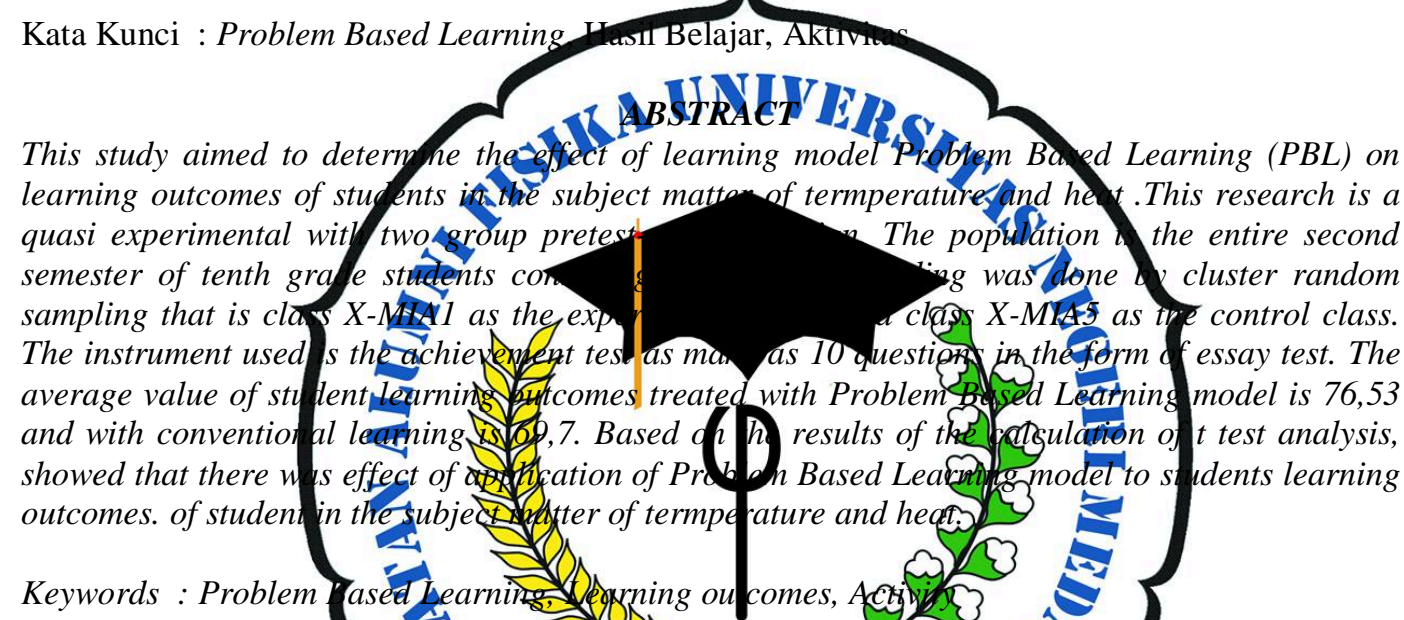

\section{PENDAHULUAN}

Pendidikan merupakan salah atu usaha untuk

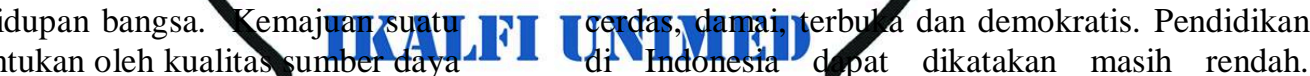
manusia (SDM). Kualitas SDM sanga Derantung pada kualitas pendidikan. Pendidikan memegon peranan penting dalam pembangunan bangsa karena berhasilnya pembangunan di bidang pendidikan akan sangat berpengaruh terhadap pembangunan di bidang yang lainnya. Pembangunan dalam bidang pendidikan sekarang ini semakin giat dilaksanakan. Berbagai cara ditempuh untuk memperoleh pendidikan, baik pendidikan secara formal maupun pendidikan secara nonformal .

Peran pendidikan sangat penting untuk menciptakan masyarakat yang cerdas, damai, terbuka dan demokratis. UU RI No. 20 Pasal 1 Tahun 2003 tentang Sistem Pendidikan Nasional telah ditetapkan bahwa "pendidikan adalah usaha sadar dan terencana untuk mewujudkan suasana belajar dan proses pembelajaran agar peserta didik secara aktif mengembangkan potensi dirinya untuk memiliki kekuatan spritual keagamaan, pengendalian diri, kepribadian, kecerdasan, akhlak mulia, serta keterampilan yang diperlukan dirinya,
Rendahnya neraldikan di Indonesia dapat dilihat dari busil belajar siswa dalam berbagai mata pelajaran. Salah satu mata pelajaran yang memiliki nilai rendah adalah mata pelajaran fisika.

Berdasarkan fakta proses belajar mengajar dilapangan bahwa guru dalam mengajarkan konsep dari teori fisika melalui kegiatan yang hanya berpusat pada guru, siswa tidak dilibatkan dalam kegiatan secara aktif dan kurang membuka kesempatan untuk mengembangkan proses berpikir siswa. Pembelajaran dengan metode ini belum memberdayakan seluruh potensi siswa sehingga sebagian besar siswa belum mampu mencapai kompetensi individual yang diperlukan untuk mengikuti pelajaran selanjutnya dan menyebabkan rendahnya hasil belajar siswa tersebut. Masalah rendahnya hasil belajar juga disebabkan oleh kurangnya atau rendahnya motivasi belajar terhadap siswa yang bersangkutan.

Berdasarkan observasi awal peneliti pada masa PPLT 2014 di SMAN 4 Kisaran bahwa pendekatan pembelajaran yang diterapkan dikelas 
masih berpusat kepada guru sehingga siswa tidak turut aktif dalam proses pembelajaran. Dalam proses pembelajaran yang digunakan adalah pembelajaran konvensional. Disamping itu, siswa juga jarang melakukan praktikum secara langsung di laboratorium karena keterbatasan waktu, mengejar materi, dan sarana prasarana yang kurang memadai, contohnya banyak alat yang telah rusak sehingga peralatan di laboratorium tidak dimanfaatkan. Hal tersebut menyebabkan siswa yang bersangkutan sulit mengingat apa yang telah dipelajarinya dan mudah dilupakan.

Berdasarkan pemaparan masalah-masalah tersebut, salah satu usaha yang dapat dilakukan oleh guru untuk memperbaikinya adalah dengan menerapkan model pembelajaran yang tepat, yang dapat melibatkan siswa secara aktif. Model pembelajaran tersebut salah satunya model problen based learning. Problem Based Learning adalah pembelajaran berdasark masalah merupakan inovasi dalam pen oelajaran karena dalam $P B L$ kemampuan berrikir siswa betul-betul dioptimalisasikan melalui proses kerja kelompok atau tim yang sistema memperdayakan, mengembangkan berkesinambungan. pelajaran yang Menurut menyuguhkan berh autentik dan bern tambahan, dalam $P B$ sebagy dalam PBE peryn (guru adala menyodorkan berbasyi macam slah autenti sehingga jelas bahwa ditunth motis swa untu dapat menyelesaikan masalah tersebul. Stetelah masalah diperoleh mak selanjutnya mefakxnomp perumusan masalah, dari asalah-masalah tersebut kemudian dipecahkan secara bersamä sqma dengan didiskusikan. Saat pemecahan masalah tersebut terdapat pertukaran informasi antararswa yang satu dengan siswa yang lainnya sehingga permasabahn yang telah dirumuskan dapat terpecahkan. Sumber informasi bukan hanya didapatkan dari guru akan tetapi dapat juga dari berbagai sumber. Guru disini berperan sebagai fasilisator untuk mengarahkan permasalahan sehingga saat diskusi tetap fokus pada tujuan pencapian kompetensi.

Berdasarkan uraian diatas, maka penulis tertarik untuk melakukan penelitian dengan judul “Pengaruh Model Problem Based Learning Terhadap Hasil Belajar Siswa Pada Materi Suhu dan Kalor di Kelas X Semester II SMAN 1 Percut Sei Tuan T.P 2014/2015".

\section{METODE PENELITIAN}

Penelitian ini dilaksanakan di SMA Negeri 1 Percut Sei Tuan kelas X semester II tahun pelajaran 2014/2015, yang beralamat di Jalan Irian Barat No.37 Ds Sampali Kec.Percut Sei Tuan, Kab. Deli Serdang. Waktu penelitian akan dilaksanakan pada semester II .
Populasi dalam penelitian ini adalah seluruh siswa kelas X SMA Negeri 1 Percut Sei Tuan Tahun Pembelajaran 2014/2015 yang terdiri dari 5 kelas.

Sampel penelitian dipilih dengan menggunakan teknik penarikan sampel kelas (Cluster Random Sampling) dimana setiap kelas memiliki kesempatan yang sama untuk menjadi sampel penelitian, sampel diambil dari populasi secara acak yaitu sebanyak dua kelas. Satu kelas dijadikan sebagai kelas eksperimen yang menerapkan model Problem Based Learning dan satu kelas lagi dijadikan sebagai kelas kontrol yang menerapkan pembelajaran konvensional.

Jenis penelitian ini adalah penelitian quasi experiment dengan desain two group pretest-postest design seperti yang ditunjukkan pada Tabel 1.

Tabel 1. Desain Penelitian tipe Two Group Pretest -Postest

\begin{tabular}{llll}
\hline Kelas & Pretes & Perlakuan & Postes \\
\hline Eksperiment & $O$ & $X_{1}$ & $O$ \\
Konftrot, & $O$ & $X_{2}$ & $O$ \\
\hline Keterangen: & & &
\end{tabular}

Keterangan:

$O=$ fustrume penelitian berupa tes

Penbelaja an Problem Based Learning

Pembetajarar konvensional.

Alat pengump ul data dalam penelitian ini adalak berbentuk raian untuk mengetahui hasil belajax siswa parda fanah kognitif dan lembar

obser(va) untuk meng tahui aktivitas siswa.

menotesis yang digunakan dengan rara gerlmen maup kelas kontrol. Data yang diperoleh ditabuasikan kemudian dicari rataratanya. Sebelun dilakukan penganalisisan data, terlebih dahy ditentukan skor masing-masing Kelompok ampel lalu dilakukan pengolahan data dengan gkah-langkah sebagai berikut:

b) Uji normalitas

c) Uji homogenitas

d) Uji kesamaan rata-rata pretes

Uji t digunakan untuk mengetahui kesamaan kemampuan awal siswa pada kedua kelompok sampel. Hipotesis yang diuji berbentuk :

$\bar{X}_{1}=\bar{X}_{2}$ : Kemampuan awal siswa pada kelas eksperimen sama dengan kemampuan awal siswa pada kelas kontrol.

$\bar{X}_{1} \neq \bar{X}_{2}:$ Kemampuan awal siswa pada kelas eksperimen tidak sama dengan kemampuan awal siswa pada kelas kontrol.

e) Pengujian hipotesis

Uji $\mathrm{t}$ digunakan untuk mengetahui pengaruh penerapan dari suatu perlakuan yaitu model Problem Based Learning terhadap hasil belajar siswa. Hipotesis yang diuji berbentuk : 


$$
\begin{aligned}
& \mathrm{H}_{\mathrm{O}}: \bar{X}_{1}=\bar{X}_{2} \\
& \mathrm{H}_{\mathrm{a}}: \bar{X}_{1}>\bar{X}_{2}
\end{aligned}
$$

Keterangan :

$$
\begin{aligned}
\bar{X}_{1}=\bar{X}_{2} \quad & \text { Tidak ada pengaruh dengan } \\
& \text { menerapkan model Problem Based } \\
& \text { Learning terhadap hasil belajar siswa } \\
& \text { pada materi suhu dan kalor di kelas X } \\
& \text { semester II SMA Negeri 1 Percut Sei } \\
& \text { Tuan T.P 2014/2015. }
\end{aligned}
$$

$\bar{X}_{1}>\bar{X}_{2}$ : Ada pengaruh dengan menerapkan model Problem Based Learning terhadap hasil belajar siswa pada materi suhu dan kalor di kelas $\mathrm{X}$ semester II SMA Negeri 1 Percut Sei Tuan T.P 2014/2015.

\section{HASIL PENELITIAN DAN PEMBAHASAN Hasil Penelitian}

Penelitian diawali dengan memberikan pretes untuk mengetahui hasil belajar siswa. Hasil pretes kelas eksperimen memperoleh nilai rata-rata 42,39 dan nilai rata-rata kelas kontrol adalah 42,16. Setelah memperoleh data hasil pretes siswa dari kelas eksperimen dan kelas kontrol, maka dilakukan pengujian analisis data dengan menggunakan uji kesamaan rata-rata pretes dimana

\begin{tabular}{|c|c|c|c|c|c|c|c|}
\hline Kelas & $\begin{array}{l}\text { Rata- } \\
\text { rata }\end{array}$ & $\mathbf{L}_{\text {hitung }}$ & $\mathbf{L}_{\text {tabel }}$ & $\mathbf{F}_{\text {hit }}$ & $\mathbf{F}_{\text {teb }}$ & $\mathbf{t}_{\text {hit }}$ & $\mathbf{t}_{\text {tab }}$ \\
\hline Eksperimen & 76,53 & 0,120 & \multirow{2}{*}{0,15} & \multirow{2}{*}{1,47} & \multirow{2}{*}{1,83} & \multirow{2}{*}{2,3} & \multirow{2}{*}{1,6} \\
\hline Kontrol & 69,7 & 0,118 & & & & & \\
\hline Kesimpulan & & Normal & & Homo & & $\begin{array}{l}\text { Ada } \\
\text { signi }\end{array}$ & $\begin{array}{l}\text { rbedaan yang } \\
\text { Kan }\end{array}$ \\
\hline
\end{tabular}
syaratnya data harus berdistribusi normal dan homogen. Hasil Hasil uji normalitas, homogenitas dan kesamaan rata-rata pretes ditunjukkan pada Tabel 2.

Tabel 2. Hasil uji normalitas, hom kesamaan rata-rata pretes

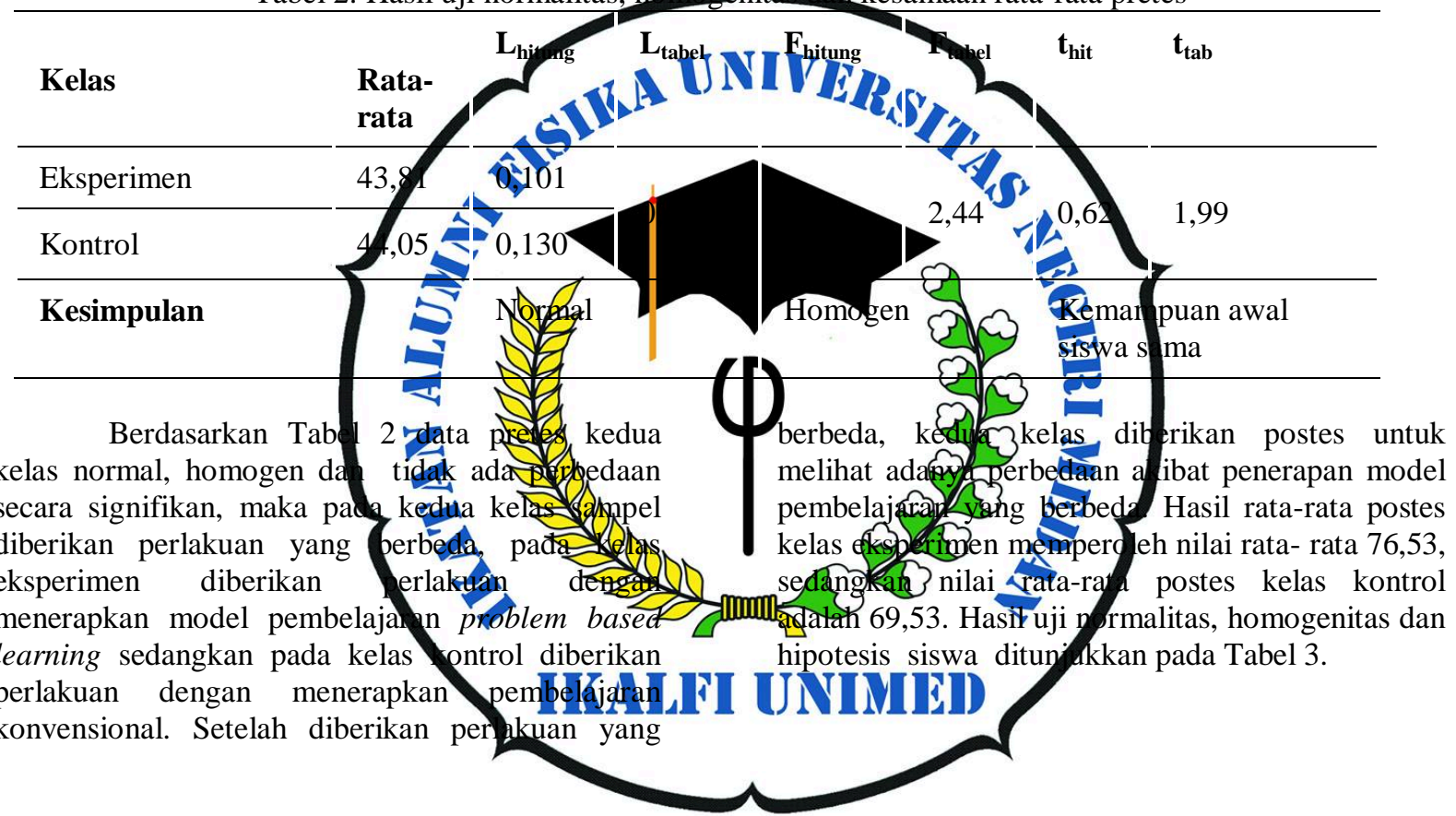

Tabel 3. Hasil Uji Normalitas, Homogenitas dan Hipotesis Siswa

Berdasarkan Tabel 3 diperoleh bahwa data $t_{\text {hitung }}>t_{\text {tabel }}$ yaitu $2,36>1,67$, sehingga dapat disimpulkan bahwa ada perbedaaan yang signifikan akibat pengaruh penerapan model pembelajaran problem based learning.

perkembangan aktivitas siswa dikelas eksperimen mengalami peningkatan selama postes kedua kelas normal, homogen dan nilai pembelajaran dengan menggunakan model pembelajaran problem based learning yaitu nilai rata-rata aktivitas belajar siswa dipertemuan I yaitu, $56,42 \%$, pertemuan II rata-rata $70,31 \%$, serta pertemuan III 80,38\%. Hal ini menunjukkan bahwa rata-rata aktivitas di pertemuan pertama dinyatakan 
cukup aktif, di pertemuan kedua dinyatakan aktif, dan di pertemuan ketiga dinyatakan sangat aktif.

Berdasarkan data di atas dapat dilihat bahwa terjadi peningkatan aktivitas pada setiap pertemuan di kelas eksperimen.

\section{Pembahasan}

Hasil penelitian menunjukkan bahwa ada pengaruh penerapan model Problem Based Learning terhadap hasil belajar siswa dengan nilai rata-rata 76,53 di kelas eksperimen, sedangkan pada pembelajaran konvensional di peroleh nilai rata-rata 69,7 di kelas kontrol

Hasil pengamatan yang dilakukan oleh observer di kelas eksperimen diperoleh bahwa pada pertemuan pertama rata-rata aktivitas siswa sebesar 56,42 . Hal ini terjadi karena siswa belum terbiasa dengan model problem based learning dan beberapa siswa kurang mengerti instruksi yang diberikan peneliti yang sesuai dengan tohom proses pembelajaran berdasarkan ma trah, namun di pertemuan kedua rata-rata 70,31 dan berikutnya di pert aktivitas sebesar 80,38. aktivitas siswa yang Problem Based Lear suhu dan kalor di ker kategori cukup aktif Kelas eksper dengan menerapkan hasil belajar ranah kelas kontrol ya pembelajaran konve sional yang sfoplumnya tela diketahui memiliki ksampaan kenan awalny yaitu 34,7 untuk kela eksperimen fir so untuk kelas kontrol dengan 1,99. Kemampuan dengan memberikan post terhadap kedua kelas. Hasil belajar yang diperolen adalah frilai ratatrat hasil belajar untuk kelas ekspecimen adalah 76,53 sedangkan untuk kelas kontro adalah 69,7. Berdasarkan data tersebut, dapat disimpulkan bahn nilai rata-rata postes kelas eksperimen lebih tinggi daripada nilai rata-rata postes kelas kontrol. dan $t_{\text {hitung }}>t_{\text {tabel }}(2,36>1,67)$, sehingga dapat disimpulkan bahwa ada pengaruh model Problem Based Learning terhadap hasil belajar siswa pada materi suhu dan kalor kelas X SMA Negeri 1 Percut Sei Tuan.

Model Problem Based Learning mempunyai tiga konsep utama yaitu pengetahuan yang didapat dari proses penyelidikan autentik yang berupa masalah, siswa dapat mengembangkan kemampuan untuk menyimpulkan dari penyelidikan yang telah dilakukan (knowledge) dan siswa menganalisis unsur-unsur yang diperlukan, melaksanakan percobaan dan mempresentasikan hasil karya. Hal ini juga didukung oleh teori konstruktivisme bahwa dalam model pembelajaran ini pengetahuan dibangun oleh siswa sendiri secara aktif baik melalui proses personal maupun sosial. Teori konstruktivis sesuai dengan model problem based learning yang mengharuskan siswa melakukan penyelidikan autentik untuk mencari penyelesaian nyata terhadap masalah nyata. Mereka harus menganalisis dan mendefinisikan masalah, mengembangkan hipotesis, dan membuat ramalan, mengumpul dan menganalisa informasi, melakukan eksperimen (jika diperlukan), membuat inferensi, dan merumuskan kesimpulan. Sudah barang tentu, metode penyelidikan yang digunakan, bergantung kepada masalah yang sedang dipelajari.

Pada kelas kontrol guru menjadi pusat pembelajaran. Sanjaya (2008) menyatakan bahwa pada pembelajaran konvensional siswa ditempatkan sebagai objek belajar yang berperan sebagai penerima informasi secara pasif, siswa lebih banyak belajar dengan menerima, mencatat, dan menghafal materi pelajaran. Dengan kata lain, pada kelas ekperimen siswa yang menjadi pusat pembelajaran. Guru pada dasarnya mengarahkan, membantu para Sis menemukan informasi dan berperan sebagai salah stu sumber belajar sehingga siswa dapat befperan vih aktif. Pada kelas kontrol guru merupan punberi informasi sedangkan siswa sebagai Rembelajaran han a berpusat pada guru sehingga cerung menjad penentu jalannya proses

S हैa KESKA PULAN Berdastctian hasil pe elitian yang diperoleh maka dapat disimputkân:

(स)) asi belajar sisy a dengan menggunakan model Soblem Based L arning pada materi suhu dan kalor di kølas semester II di SMA Negeri 1 Percut Sei Tua T.P 2014/2015 diperoleh nilai ratarata 6.53 dengan kategori baik. (2) Hasil belajar siswa dengan menggunakan pembelajaran kon ensional pada materi suhu dan kalor di kelas X semester II di SMA Negeri 1 Percut Sei Tuan T.P 2014/2015 diperoleh nilai rata-rata 69,7 dengan kategori baik. (3) Aktivitas belajar siswa yang diberi perlakuan dengan model Problem Based Learning mengalami peningkatan dengan nilai ratarata aktivitas pada pertemuan I sebesar 56,42, pada pertemuan ke-II nilai rata-rata aktivitasnya 70,31 dan nilai rata-rata aktivitas pada pertemuan ke- III 80,38 dengan kategori di setiap pertemuan dinyatakan cukup aktif, aktif dan sangat aktif. (4) Ada pengaruh yang signifikan dengan menerapkan model Problem Based Learning pada kelas eksperimen dengan pembelajaran konvensional. Dengan $t_{\text {hitung }}$ lebih besar dari $t_{\text {tabel }}$ yaitu 2,36 > 1,67 . Saran

Saran yang dapat peneliti ajukan berdasarkan pembahasan adalah sebagai berikut: (1)Untuk peneliti selanjutnya diharapkan lebih mengoptimalkan pengelolaan kelas khususnya pada saat diskusi berlangsung agar tidak terjadi kegaduhan-kegaduhan di dalam kelas. (2) Kepada 
peneliti selanjutnya yang ingin meneliti tentang Model Pembelajaran PBL, ada baiknya memberikan motivasi terlebih dahulu kepada siswa yang akan mempresentasekan hasil karya untuk meningkatkan rasa percaya diri pada siswa tersebut. (3) Dari hasil penelitian maka dianjurkan untuk peneliti selanjutnya agar lebih meningkatkan lagi nilai rata-rata siswa tersebut.

\section{DAFTAR PUSTAKA}

Arends, R. I., (2008), Learning to Teach Edisi Ketujuh Buku Satu, Pustaka Pelajar, Yogyakarta.

Arends, R. I., (2008), Learning to Teach Edisi Ketujuh Buku Dua, Pustaka Pelajar, Yogyakarta.

Arikunto, S., (2010), Prosedur Penelitian, PT Rineka Cipta, Jakarta.

Dimyati dan Mujdiono, (2009), Belaja atan Pembelajaran, Rineka Cipta, Jakarta

Djamarah Saiful Bshri, (2001), Rineka Cipta, Jakarta

Joyce, B., Weil, M. dan Models of Teaching: Mo Pustaka Pelajar, Yogyak

Matlin, M. E. (2009). Cogn Seventh Edition. Intern Jhon Wiley \& Sons, In Sagala, S., (2009), Konsep Pembelajaran, CV Alf
Sanjaya., W, (2010), Strategi Pembelajaran Berorientasi Standar Proses Pendidikan, Prenada Media Grup, Jakarta

Sardiman, (2009), Interaksi dan Motivasi Belajar Mengajar, PT Raja Grafindo Persada, Jakarta.

Sihotang, P.S, (2014), Pengaruh Model Problem Based Learning terhadap Hasil Belajar Siswa Pada Materi Kalor di Kelas X Semester II SMA N 02 Pematangsiantar T.P 2013/2014. Skripsi. FMIPA UNIMED,Medan.

Slameto, (2010), Belajar dan Faktor-faktor yang Mempengaruhinya, Rineka Cipta, Jakarta.

Sudjana, (2001), Metode \& Teknik Pembelajaran Partisipatif, Falah Production, Bandung

Sudjana,. (2005). Metode Statistika, Tarsito, Bandung

Sukadinata. Nana. S, (2003), Landasan Psikologi Proses Pendidikan, Remaja Rosdakarya, Bandung.

Surya,yonnes. (1997). Olimpiade Fisika. Jakarta : TJ NT TPenerbit PYPrimatika Cipta Ilmu

Syahr. Ayshibbin, (2008). Psikologi pendidikan Dengan Ṕendekan Baru, Remaja Rosdakarya, Bandung. $4 / 5$
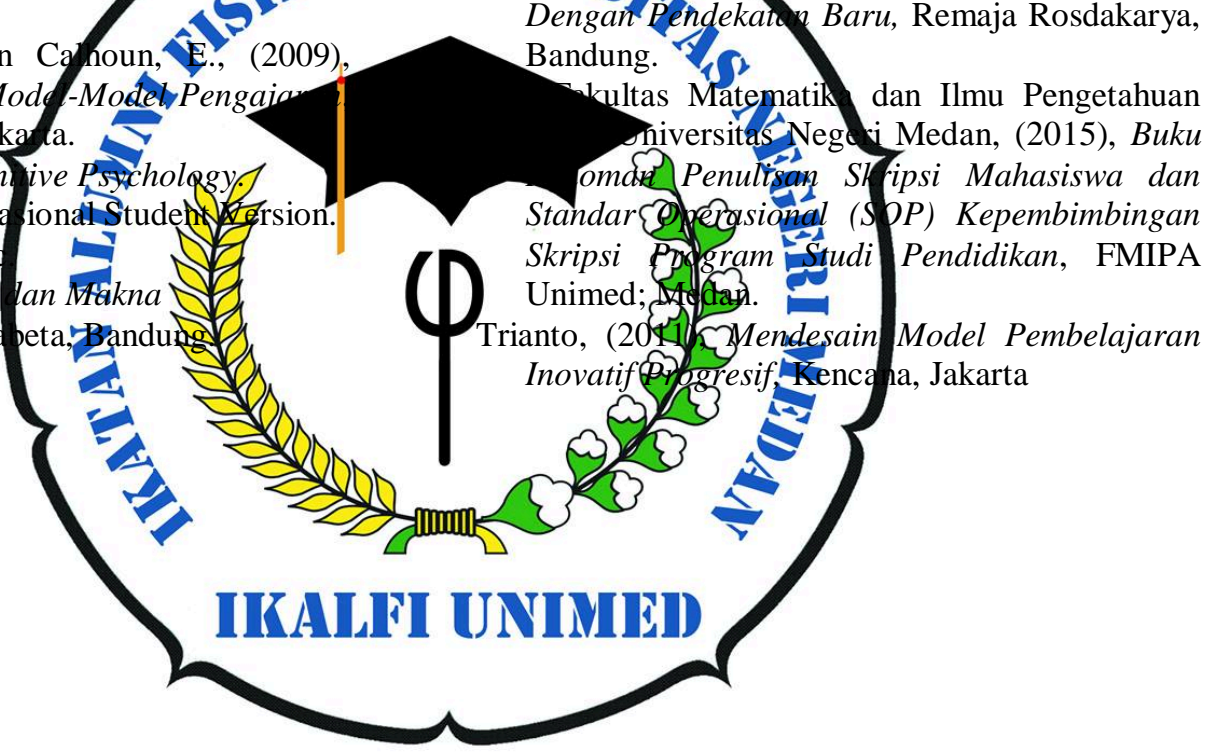